\title{
Inappropriate Reviewer Assignment that Causes Education Inequality in Peer Assessment
}

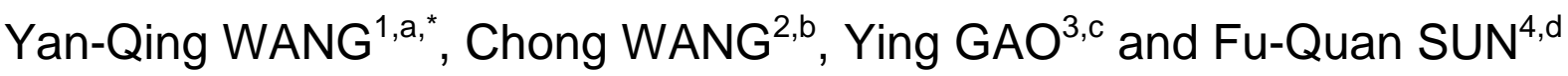 \\ ${ }^{1}$ School of Management, Harbin Institute of Technology, Heilongjiang 150001, China \\ ${ }^{2}$ School of Business, Nanjing Audit University, Nanjing 211815, China \\ ${ }^{3}$ School of Foreign Languages, Northeast Normal University, Jilin 130024, China \\ ${ }^{4}$ School of Mathematics \& Statistics, Northeastern University at Qinhuangdao, Hebei 066004, \\ China \\ ayanqing@hit.edu.cn, bzgwangc@sina.cn, gaoy687@nenu.edu.cn, dsunfq@neuq.edu.cn \\ ${ }^{*}$ Corresponding author
}

Keywords: Peer Assessment (PA), Reviewer Assignment, Education Inequality, Reviewer Assignment Strategy, Zone of Proximal Development (ZPD)

\begin{abstract}
The equality of educational opportunity might have been concerned since the first school opened. Any extra care or consideration for low-competency students is welcome and heartwarming. Peer assessment, offline or online, is becoming a very successful learning vehicle beyond a quality assurance approach. However, when instructors assign (or operate computer to assign) reviewers for authors' work, they may generate education inequality intentionally or unintentionally. We list out four typical reviewer assignment patterns and analyze their possible consequence and the inequality they may bring out. We find that inequality occurs explicitly when two students with small or little competency difference are assigned as a review pair, and it occurs implicitly when peers have big competency difference. Based on ZPD theory, we suggest an adjacent-first assignment strategy and point out several interesting future research topics.
\end{abstract}

\section{Introduction}

Inequality of education has drawn great attentions from educators and scholars for a long time. In about 2500 years ago, one of the greatest educators in ancient China, Confucius stated that "with education there is no distinction between classes or races of men". He pointed out that everybody does have equal right to accept education, regardless of his/her race and class. Also, many western scholars had great concerns about educational equality [1]. Actually, inequality may exist in any case of educational settings if the process is not managed well.

As an efficient learning vehicle, peer assessment (PA) (also named peer review, peer evaluation or peer feedback) is widely applied in diverse cases of education. In Topping's highly cited review, it was defined as "an arrangement for learners to consider and specify the level, value, or quality of a product or performance by other equal-status learners" [2]. The worth of PA is widely illustrated especially in educational context [3-6]. In PA, every author's work should be assigned to one or more reviewers before assessment starts. As a critical step of PA, reviewer assignment has a huge impact on not only satisfaction of participants but 
educational equality. There are several known online PA systems, such as Calibrated Peer Review [7], Expertiza [5], SWoRD[4], and EduPCR [6, 8, 9].

$\boldsymbol{E d u P C R}$ (peer code review in educational context) is an online PA system for programming language learning. It is suitable for undergraduates, postgraduates, and junior college students who need to learn programming skills. In EduPCR, every learner is required to participate the phases including completing programming task, reviewing peer's work, revising own program, doing back-evaluation, etc. Instructor sets tasks and summarizes final scores of students. Computer assigns reviewers for peers, according to the algorithms chosen or configured by instructor [6].

Since 2004, EduPCR has been updated for several times. It is applied in the learning and evaluation process of three courses, including $C++, C$ Programing, and Object-Oriented Programming in Java, in the School of Software and the School of Management at Harbin Institute of Technology. With this novel learning approach, students improve greatly in their high-order capabilities, such as analyzing, expressing in writing, critical thinking, and innovative thinking.

SWoRD (Scaffolded writing and reviewing in the discipline) is an online PA platform [4]. Drafts are distributed randomly and anonymously to (usually five) students for review. Reviewers are required to grade each essay on seven-point rating scales (with anchors that are specific to each reviewing scale) and write specific feedback for each writing dimension as specified by their instructor to match the focus of the given writing assignment.

After the reviewers have submitted the ratings and comments, the authors receive their peers' feedback and a mean rating on each writing dimension. With the received peer comments and ratings, students produce a second draft, which can then be peer reviewed again. With SWoRD, after receiving each round of reviews and ratings, the authors also rate the helpfulness of the reviews they have received on a five-point rating scale: this step is called back-evaluation. Reviewers receive a helpfulness grade based upon the mean helpfulness ratings they receive. This step provides accountability for higher quality comments.

In summary, in online PA systems including SWoRD and EduPCR, reviewer assignment problem exists accordingly. For example, in EduPCR, reviewers are assigned by computer (actually by instructor's configuration) or assigned according to some designed strategies [10]. The risk of attempting novel reviewer assignment strategy is that it may raise the question of opportunity inequality. Even for SWoRD, in which the reviewer assignment is done randomly, opportunity inequality might happen because the opportunity of making pairs is uncontrolled.

\section{Definitions and Patterns of Reviewer Assignment in PA}

\section{Basic Definitions}

Academic Competency. It stands for comprehensive academic capability of a student, including background knowledge and skills. This measure is hard to scale because lots of factors affect it. Fortunately, in a specific course, we can take a student's update average score as his/her academic competency. With the iteration of PA tasks, academic competency becomes more and more accurate.

Competency Level. Because studying a specific student's competency is not only inaccurate but impractical, we classify students into several competency levels. In our experience, five is 
the recommended number of levels because seven is too big and three is to rough. Thus, we have five levels (high $=1$; moderately high $=2$; middle $=3$; moderately low $=4$; low $=5$ ).

Assignment Dyad. When we assign a student with one competency-level to review the work of a peer with another competency-level, we get an assignment dyad, in form of \{reviewer, author\}. We focus on the assignment between the reviewers and authors with a certain competency-level, not considering specific students.

Competency Growth. It denotes how much a student increases his/her competency during a PA task. Actually, in a PA activity, both author and reviewer get competency growth more or less. For example, when reading author's work, a review can learn some through reflection, analysis, and critical thinking, etc.

\section{Typical Assignment Patterns}

Although Tudge et al. demonstrated an exception [11], the majority of research indicates that children who work with a more competent partner improve more than those who have an equally or less competent partner [12]. Therefore, it is rational that most students would like to be assigned with a more competent peer. However, because the number of high-competency students is limited one in practice, the students in different competency-level may have different education opportunities when instructors apply different reviewer assignment patterns.

According the competency difference between assigned pairs, we summarize four typical and frequently used patterns, as shown in Table 1.

Pattern 1: \{high, low\}. Sometimes, for taking care of the students with low-competency, some instructors assign manually (or automatically by choosing a certain computer algorithm) high-competency reviewers to the work of low-competency students intendedly. It is a warm-hearting behavior, of which the instructors often take pride.

Pattern 2: \{low, high\}. Similar to Pattern 1, some instructors offer chance to low-competency students, (as reviewers) and let them to review the work by high-competency authors. The purpose of this arrangement usually is to increase the opportunities for the students with low-competency to "enjoy" or "imitate" the artifacts by high-competency authors.

Pattern 3: \{high, high\}. Dislike Pattern 1 and Pattern 2, if an instructor wishes one or several high-competency students to stand out from the crowd, this pattern is adopted. In general, the purpose of Pattern 3 includes showing excellent talents, pursuing important awards, or just satisfying instructor's feeling of achievement. High-competency students might be happy because they are assigned to students with approximately equal academic competency. They usually encounter few obstacles of communicating with peers and understanding peers' work or comments.

Pattern 4: \{low, low\}. Because number of high-competency students is limited, Pattern 4 coexists with Pattern 3 generally. In another word, Pattern 4 results from Pattern 3. In this pattern, low-competency students have little opportunity of studying together with high-competency ones in pairs. Thus, low-competency students are likely to feel "discriminated" or "isolated". 
Table 1. Four typical patterns of reviewer assignment in PA

\begin{tabular}{|c|c|c|c|}
\hline Pattern \# & Reviewers' level & Authors' level & Competency difference \\
\hline 1 & high & low & big \\
\hline 2 & low & high & big \\
\hline 3 & high & high & little \\
\hline 4 & low & low & little \\
\hline
\end{tabular}

\section{Education Opportunities Analysis in PA}

We summarize the happiness of participants, the possible consequence, and the hidden inequality in the four typical patterns just mentioned, as shown in Table 2. We find into two objectives commonly applied, as follows.

\section{Objective 1: Helping the Weak}

It includes Pattern 1 and Pattern 2. In these two patterns, opportunity of cooperating with high-competency student is presented to low-competency student. It is seemingly promoting opportunity equality, however, may cause education inequality by generating disharmony.

Ellis and Rogoff indicate that the more competent partner understands what the less advanced partner needs and is able to adjust the degree of support they give to match that [13]. However, we believe that the assignment strategy in Pattern 1 and Pattern 2 is not likely to be beneficial to either reviewer or author.

In Pattern 1, a high-competency reviewer reviews the work of a low-competency author. For the reviewer, the work of the author may be poorly written and the reviewer may feel bored to read this kind of work many times. As a result, the reviewer may barely "finish" the review. In this situation, one can imagine how much the author will benefit from the reviewer's comments.

In Pattern 2, even though the low-competency reviewer has an opportunity to read any enjoy the possibly well-written work by the high-competency author, the result may be not satisfactory. Because low-competency reviewer may have insufficient knowledge or skill, the work by high-competency author might be hard to understand by the reviewer. At least, the reviewer cannot find most of the merits in the author's work. In this scenario, it is hard to hope that the review comment or suggestions by the reviewer would be helpful to the author.

In both Pattern 1 and Pattern 2, it looks like the unfairness exists in high-competency side (reviewer in Pattern 1 and author in Pattern 2). However, in fact, it is not beneficial to the low-competency participants in these two patterns. Because PA is an interactive learning process, how could a participant be happy alone while his/her peer feels unfair or angry?

\section{Objective 2: Cultivating Elites}

It consists of the Pattern 3 and Pattern 4. In these two patterns, low-competency students have little opportunity to cooperate with high-competency students. It is obviously arousing opportunity inequality.

In Pattern 3, both reviewer and author may be happy because they can understand peer's work and may learn or reflect from peer's work. They may lose sight of unfairness or education inequality because they need not to consider it. Staying in a "Paramount Club", both the reviewer and author may make big progress in learning. 
In Pattern 4, when reviewer and author know that they are discriminated by assigning within low-competency students, they probably feel unhappy and regard the assignment is unfair. In addition to this kind of bad feeling, they hardly learn very valuable knowledge or skill from their peers.

Thus, in Pattern 3 and Pattern 4, the Harriet Effect is likely to be the consequence of reviewer assignment strategy.

Table 2. Summary of four typical reviewer assignment patterns

\begin{tabular}{|c|c|c|c|c|c|}
\hline Pattern \# & Pattern & $\begin{array}{c}\text { Competency } \\
\text { difference }\end{array}$ & Who's happy & Possible consequence & $\begin{array}{c}\text { Who feels } \\
\text { unfair }\end{array}$ \\
\hline 1 & high->low & big & - & small growth by both & r \\
\hline 2 & low->high & big & - & little growth by both & a \\
\hline 3 & high->high & little & r, a & Harriet effect & - \\
\hline 4 & low->low & little & - & Harriet effect & r, a \\
\hline
\end{tabular}

Note: $r=$ reviewer, $a=$ author, $-=$ none

\section{Suggestions on Minimizing the Inequality in PA}

In summary, to decrease the possibility of inequality in PA, some well-designed reviewer assignment strategies should be developed. Hereby, we make some suggestions as follows:

(1) Clustering students into some levels, e.g. five.

(2) Referring to ZPD theory by Vygotsky, assign reviewers and authors in adjacent levels. It is suggested to control the level of reviewer one superior to that of author.

(3) Defining several assignment rule matrices (see Figure 1) to make the assignment optional and controllable. Matrix is used to control the priority of reviewer assignment.

For example, the Objective 1 mentioned above can be named as equal-level-first (Eq) (see Eq part of Figure 1). In $E q$, the $1 \mathrm{~s}$ in diagonal line are red-circled, which means they get the highest priority when assignment algorithm is running. Similarly, the Objective 2 can be remarked as cross-level-first $(\mathrm{Cr})$ (see $\mathrm{Cr}$ part of Figure 1) and the 1 s circled in red denote the cases in Pattern 1 and Pattern 2.

For assigning reviewers in adjacent levels, two examples of assignment rule matrices are shown in $A C$ and $A E$ of Figure 1. They could be labelled as adjacent-cross-first $(A C)$ and adjacent-equal-first $(A E)$. $A C$ means that adjacent peers have the top priority of being assigned in pairs and those in cross-level has the second priority. $A E$ refers to that the assignments of students with adjacent-level and equal-level competency has first and second priority accordingly.

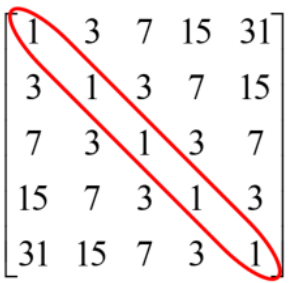

$\mathrm{Eq}$

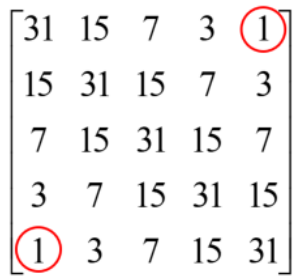

$\mathrm{Cr}$

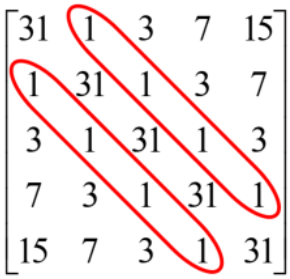

$\mathrm{AC}$

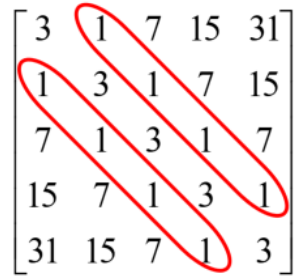

$A E$

Figure 1. Four constructed assignment rule matrices 


\section{Discussion and Future Work}

Education inequality still happens in a random reviewer assignment situation. In EduPCR, the designed assignment rule matrices are being verified to decrease the inequality in learning. In some online PA systems such as SWoRD, random reviewer assignment strategy is deployed for considering equality. However, random assignment does not assure actual education equality. As we analyzed in Table 2, even though the pairs are generated randomly by computer, reviewers in Pattern 1 and 4 and authors in Pattern 2 and 4 may experience unfairness. Thus, the suggestion depicted in this study looks like a practical solution, not only for learning performance but for education equality.

Along with the ideas in this study, there are some topics worthy of studying.

- Assignment rule matrix should be further developed. On the one hand, they should be scrutinized in theory. On the other hand, more matrices than four could be constructed. Furthermore, the assignment rule matrices in this study should be empirically verified before they become feasible in reviewer assignment practice.

- Vygotsky's ZPD is very instructive to reviewer assignment study. The relationship of ZPD and adjacent-first assignment is an appealing topic.

- The educational inequality hidden in random reviewer assignment strategy might be a challenging and controversial research topic.

\section{Acknowledgement}

This work was partially supported by National Natural Science Foundation of China [no.71573065 and no.71571085], Ministry of Education of China (no.201602016006).

\section{References}

[1] J. Tooley, Equality of educational opportunity without the state? Studies in Philosophy and Education 12(2-4) (1993) 153-163.

[2] K. Topping, Peer assessment between students in colleges and universities, Review of Educational Research 68(3) (1998) 249-276.

[3] X. Li, Incorporating a code review process into the assessment, In the 20th Annual Conference of the National Advisory Committee on Computing Qualifications, Nelson, New Zealand, (2007) 125-131.

[4] C. D. Schunn, Writing to learn and learning to write through SWoRD, in: S.A. Crossley \& D. S. McNamara (Eds.), Adaptive Educational Technologies for Literacy Instruction, NY: Taylor \& Francis, Routledge, 2016, pp. 243-259.

[5] E. F. Gehringer, Expertiza: Managing Feedback in Collaborative Learning, in: A. Juan, T. Daradoumis, F. Xhafa, S. Caballé, \& J. Faulin (Eds.), Monitoring and Assessment in Online Collaborative Environments: Emergent Computational Technologies for E-Learning Support, Hershey, PA: IGI Global, 2010, pp. 75-96.

[6] Y. Wang, H. Li, Y. Feng, Y. Jiang and Y. Liu, Assessment of programming language learning based on peer code review model: Implementation and experience report, Computers \& Education, 59(2) (2012) 412-422. 
[7] A. A. Russell, Calibrated Peer Review: A Writing and Critical-Thinking Instructional Tool, in: M. Druger, E. D. Siebert, and L. W. Crow (Eds.), Teaching Tips: Innovations in Undergraduate Science Instruction, Arlington: National Science Teachers Association, 2004, pp. 54-55.

[8] Y. Wang, W. Ai, Y. Liang and Y. Liu, Towards motivating participants to assess peers' work more fairly: taking programming language learning as an example, Journal of Educational Computing Research, 52(2) (2015) 180-198.

[9] Y. Wang, Y. Jiang, M. Chen and X. Hao, E-learning-oriented incentive strategy: Taking EduPCR system as an example, World Transactions on Engineering and Technology Education 11(3) (2013) 174-179.

[10] Y. Wang, F. Sun, How to choose an appropriate reviewer assignment strategy in peer assessment system? Considering fairness and incentive, in proceeding of 2018 Annual International Conference on Education and Social Development (ESD'2018), May 18th-20th, 2018, Xi'an, China. (in press)

[11] J. R. H. Tudge, S. A. Putnam and J. Valsiner, Culture and cognition in developmental perspective, in: B. Cairns, G. H. Elder, Jr., \& Costello, E. J (Eds.), Developmental science, New York: Cambridge University Press, 1996, pp. 190-222.

[12] D. M. Hogan, J. R. H. Tudge, Implications of Vygotsky's theory for peer learning, in: A. M. O'Donnell \& A. King (Eds.), The Rutgers Invitational Symposium On Education Series. Cognitive perspectives on peer learning, Mahwah, NJ, US: Lawrence Erlbaum Associates Publishers, 1999, pp. 39-65.

[13] S.Ellis, B. Rogoff, The strategies and efficacy of child vs. adult teachers, Child Development, 53 (1982) 730-735. 